\title{
Coordination and Profit Optimization by Producer-Distributor System of Agricultural Products in Bangladesh
}

\author{
Mohammad Khairul Islam, ", Mohammad Mahmud Alam², Mohammed Forhad Uddin ${ }^{3}$, \\ Gazi Mohammad Omar Faruque ${ }^{4}$ \\ ${ }^{1}$ Department of Mathematics, Directorate of Secondary and Higher Education, Dhaka, Bangladesh \\ ${ }^{2}$ Department of Mathematics, Dhaka University of Engineering and Technology, Gazipur, Bangladesh \\ ${ }^{3}$ Department of Mathematics, Bangladesh University of Engineering and Technology, Dhaka, Bangladesh \\ ${ }^{4}$ Department of Computer Science and Engineering, University of South Asia, Dhaka, Bangladesh
}

Email address:

khairulamc@gmail.com (M. K. Islam), alamdr.mahmud@yahoo.com (M. M. Alam), kforhad77@gmail.com (M. F. Uddin), info@southasiauni.edu.bd (G. M. O. Faruque)

*Corresponding author: khairulame@gmail.com

\section{To cite this article:}

Mohammad Khairul Islam, Mohammad Mahmud Alam, Mohammed Forhad Uddin, Gazi Mohammad Omar Faruque. Coordination and Profit Optimization by Producer-Distributor System of Agricultural Products in Bangladesh. American Journal of Applied Mathematics. Vol. 8, No. 1, 2020, pp. 22-28. doi: 10.11648/j.ajam.20200801.14

Received: October 28, 2019; Accepted: November 15, 2019; Published: February 4, 2020

\begin{abstract}
This study, presents three different mathematical models: Producer, Distributor and Coordination modelwhich negotiate with a Producer-Distributor system for producing and distributing ofagricultural products in Bangladesh. In this paper, we investigated supply chain network $(\mathrm{SCN})$ are two distinct freelance supply organizations. SCN management has the difficulties for the disconnected and freelance economic people. Further, fast technological changes and high fight build SCN a lot of complicated. The problem of locating distribution centers (DCs) is one among the foremost necessary problems in design of SCN. Current study, SCN was modeled using a formulation in mixed integer linear programming (MILP) problem, in which the facilities are coordinated by mutually sharing information with each other between producer and wholesaler. We think, this research presents a real life coordination optimization problem. The formulated MILP model is solved by using a mathematical programming language (AMPL) and results obtained by appropriate solver MINOS.
\end{abstract}

Keywords: Agricultural Products, Mixed Integer Linear Programming, Coordination, Optimization, Bangladesh

\section{Introduction}

Supply Chain Management is outlined because the coordination of the physical, logical and money flows management between the supply chain networks $(\mathrm{SCN})$ Brandenburg et al. [1], that final goal is to deliver the proper product, within the correct amount, at the proper time, for the proper client, aspiring to with efficiency answer client demand Wang et al.[2]. The SCN style and designing may be a complicated method Nickel et al.[3], though it's proved that associate economical SCN style and resource allocation over the network is crucial for a decent performance of the SCN Papageorgiou [4]. Additionally, since business surroundings are continually ever-changing Gupta and Maranas [5], account for uncertainty inside the SCN style and designing is extremely necessary Klibi and Martel [6].

Historically, SCN style and designing improvement has been supported economic edges Guillen-Gosalbez and Grossmann [7]. However, because of accumulated competitive, government pressures and client awareness Sundarakani et al. [8]. Thus, within the 90s the thought of property within the management literature has emerged. In addition, began to seem ideas like inexperienced supply chains Ramudhin et al. [9]; property supply chain management Hassini et al.[10]; and, triple bottom line Bojarski et al. [11] and completely different transportation modes Wang et al. [12]. 
Managing a SCN may be a complicated method, but manage a agricultural products supply chain is even more difficult due to: restricted and short shelf lives, temperature and wetness necessities, restrictions relating to time windows for product deliveries, high client expectations, low profit margins Akkerman et al. [13], perishability, long supply lead times, supply and demand uncertainties, want of nice investments in technology, facilities and labor Ahumada and Villalobos [14], maintain product quality and analyzed the management of these SCN Rong et al. [15] and safety Aung and river [16]. Finally, the environmental impacts are a priority in food provide chain management Van der Vorst et al. [17], and there's proof that improve the operational activities, like transportation and contributes to cut back the postharvest wastage Shukla and Jharkharia [18].

A vast quantity of literature obtainable on SCM analysis, was coping with the various aspects of the topic. Various models, abstract likewise as quantitative, talk to designing and quantitative aspects of various business functions location, production, inventory and transportation considering these areas for combined optimization. In the literature, a single-vendor and a single-buyer inventory models introduced by Goyal [19] in order to optimize the joint total cost. Sajadieh, M. S. and Jokar M. R. A. [20], Optimizing shipment, ordering and pricing policies in a two stage supply chain with price sensitive demand, projected models embrace combination of two, or a lot of those areas. Facility location problems (FLP), that area unit usually accustomed style distribution networks, involve decisive the sites to put in resources, likewise because the assignment of potential customers to those resources. Drezner et al.[21] shortly delineated FLP the situation of producing plants, the assignment of ware homes to those plants, and at last the assignment of outlets to every warehouse. Apart from geographical boundaries, Hung et al. [22] delineated the situation allocation with reconciliation needs among Distribution Centre (DC). They developed a bi-level programming model to attenuate the whole price of the distribution network, and balanced the work load of every DC for the delivery of product to its client, resolution the model by the genetic rule

Jose et al. [23] presented mixed integer linear programming to solve a capacitated vehicle routing drawback minimizing number of auto and move time. They enforced the model to a true life drawback of a distribution company and solved it numerically. They obtained a possible answer to the developed model considering six delivery points with some characteristics. They additionally investigated the interaction between transport networks and provide chain networks. By numerical example, they showed that by the event of transport network it's doable to enhance the potency of offer chain networks

In this study, producer-wholesaler multi-product, multidistribution center and multi-customer location production problem is formulated as a MILP model which maximizes the total profit, and at the same time optimizes production land, profitable distribution center. We have incorporated the possibility of external procurement by the producer when it faces shortages and extended the model by considering the interested of the wholesaler also as long term partnership is described by the business entities in today's business environment. The wholesalers purchase the item from the producer and sell it in the market. To solve these formulated MILP model using a mathematical programming language (AMPL) with appropriate solver MINOS. Finally, a numerical example along with the sensitivity of demand risk factor is considered to estimate the achievement of the models.

The rest of this study is organized as follows: section 2 discusses data ingathering. In section 3 presentsthree mathematical formulation of MILP model which deals with the stage of research methodology. In section 4 , discuss the solution procedureandnumerical example. In section 5, discuss the results and sensitivity of the MILP model. Finally, in section 6 , presents the conclusions and suggestions for the future work.

\section{Data Ingathering}

Data ingathering may be a crucial step, since the standard of information collected influences the results of the study. If the results accuracy defines the problem under study, those results enable deeper information of the problem. Typically this stage consumes a long time, and contributes to correct information and to supply input to the mathematical model.

We tend to developed our MILP model by ingathering information for agricultural product optimization in at random elite samples of 235 market players who are directly or indirectly concerned in agricultural business from four districts in Bangladesh, additionally the data gathered for this study area unit associated with customers and suppliers; types of products; fixed and variable prices associated to installation of plants, warehouses, distribution centers and agricultural products hub facilities; transportation prices, process and transportation times associated to transportation modes. The mathematical model consists in an exceedingly ancient SC, during which flows area unit initiated from suppliers and finish in customers. Thus, the SCN consists within the following entities: suppliers, productions facilities, DC, WH, agricultural products hubs and markets. Every entity is delineated by its geographical location and therefore the entities area unit connected through the fabric flows between them.

\section{Mathematical Model Formulation}

This section describes the proposed mathematical formulation. Before mathematical formulation of MILP models, we have discussed indices, sets, parameters and decision variables that are relevant with our work in this study.

Sets:

$L$ : Set of production locations indexed by $l$;

$C$ : Set of customers indexed by $j$; 
$P$ : Set of products indexed by $i$

$D$ : Set of distribution center indexed by $k$.

Parameters for producer model:

$u_{i l}$ The price of $i^{\text {th }}$ product at $l^{\text {th }}$ location $(\$ / \mathrm{kg})$

$l_{i l}$ Labor Requirement of $i^{\text {th }}$ product at $l^{\text {th }}$ location (ha)

$v_{i l}$ Labor cost of $i^{\text {th }}$ product at $l^{\text {th }}$ location (\$/unit)

$w_{i l}$ The amount of water need of $i^{t h}$ product at $l^{t h}$ location (ha)

$g_{i l}$ Water cost of $i^{t h}$ product at $l^{\text {th }}$ location (\$/unit)

$f_{i l}$ Fertilizer Requirement of $i^{\text {th }}$ product at $l^{\text {th }}$ location ( $\mathrm{kg} / \mathrm{ha})$

$c_{i l}$ The price of unit raw materials for $i^{\text {th }}$ product at $l^{\text {th }}$ location (\$/unit)

$r_{i l}$ The amounts of raw materials need to produce $i^{t h}$ product at $l^{\text {th }}$ location (\$/unit)

$t_{i l}$ Unit transportation costof raw materials for $i^{\text {th }}$ product at $l^{\text {th }}$ location (\$/unit)

$p_{i l}$ The production cost of $i^{\text {th }}$ product to $l^{\text {th }}$ location at (\$/unit).

$h_{i l}$ Unit holding cost of $i^{\text {th }}$ product from $l^{\text {th }}$ location for some given unit of time (\$/unit-time)

$g^{*}{ }_{i l}$ Fertilizer cost of $i^{t h}$ product at $l^{\text {th }}$ location (\$/unit).

$p_{i}$ Uncertainty probability of $i^{t h}$ product

$d_{i j}$ Unit demand of $i^{t h}$ product for $j^{\text {th }}$ customer

TCLA, is the total cultivated land available

$T W A$, is the total amount of water available

Parameters for wholesaler model:

$U_{l i}^{1}$ Annual fixed cost for $l^{\text {th }} \mathrm{DC}$ operation of $i^{\text {th }}$ product

$U_{l}^{2}$ Annual fixed cost for $l^{\text {th }} \mathrm{DC}$ operation

$U_{l i}^{3}$ Unit producing cost of $i^{t h}$ product for $l^{\text {th }} \mathrm{DC}$

$U_{\text {lij }}^{4}$ Unit shipment cost of $i^{\text {th }}$ product for $j^{\text {th }}$ customer through $l^{\text {th }} \mathrm{DC}$

$U_{l i}^{5}$ Unit holding cost of $i^{\text {th }}$ product for $l^{\text {th }} \mathrm{DC}$

$U_{\text {lij }}^{6}$ Unit transportation cost of $i^{t h}$ product for $j^{\text {th }}$ customer through $l^{\text {th }} \mathrm{DC}$

$D_{I J}$ Unit demand of $i^{\text {th }}$ product from $j^{\text {th }}$ customer

$C a_{l I}$ Products capacity of $i^{\text {th }}$ product for $l^{\text {th }} \mathrm{DC}$

$T_{l j}$ Unit transportation time from $l^{\text {th }} \mathrm{DC}$ to $j^{\text {th }}$ customer

\subsection{Decision Variables for Producer}

$x_{l i j}$, is the total amount of $i^{\text {th }}$ product shipped from $l^{\text {th }}$ location/distribution center for ${ }^{\text {th }}$ customer $(\mathrm{kg})$

$$
x_{l}=\left\{\begin{array}{l}
1, \text { if location } l \text { is used }, \\
0, \text { else }
\end{array}\right.
$$

$W_{l j}=\left\{\begin{array}{l}1, \text { if customer } j \text { is used distribution center } l, \\ 0, \text { else }\end{array}\right.$

\subsection{Producer Model}

Objective function,

$$
\text { Maximize, } Z=Z_{1}-Z_{2}
$$

Where,

$$
Z_{1}=\sum_{l=1}^{L} \sum_{i=1}^{m} \sum_{j=1}^{n} U_{l i} X_{l i j}
$$

$x_{l i j}, F_{l i}, W_{l i}, L_{l i}, h_{l i}, p_{l i}, c_{l i}, r_{l i}, v_{l i}, f_{l i}, w_{l i}, l_{l i}, g_{l i}, g_{l i}^{*}, t_{l i}, u d_{l i j}$, TCLA, TLA, TWA, TFA are non-negative and $x_{l}$ is binary,(9)

Equation (1) represents the difference between return and investment, (2) and (3) are the total return and total investment. An equation (4), (5), (6), (7), (8) and (9) denotesthe land, labor, water, fertilizer, demand and nonnegative constraints for producer.

\subsection{Distributor Model}


The objective function of the model is difference between total income and total cost:

$$
\text { Maximize, } Z^{*}=Z_{3}-Z_{4}
$$

Where $z_{3}$ is the total income and $z_{4}$ is the total cost.

$$
Z_{3}=\sum_{l=1}^{L} \sum_{j=1}^{n} \sum_{i=1}^{m} X_{l i j} S_{l i}^{* *}
$$

Subject to constraints:

$$
\begin{aligned}
& Z_{4}=\sum_{l=1}^{L} \sum_{i=1}^{m} V_{l} u_{l i}^{1}+\sum_{l=1}^{L} \sum_{j=1}^{n} \sum_{i=1}^{m} X_{l i j} u_{l j i}^{2}+\sum_{l=1}^{L} \sum_{j=1}^{n} \sum_{i=1}^{m} X_{l i j} u_{l j i}^{3} \\
& +\sum_{l=1}^{L} X_{l} u_{l}^{4}+\sum_{l=1}^{L} \sum_{j=1}^{n} \sum_{i=1}^{m} X_{l i j} u_{l j i}^{5} / 2+\sum_{l=1}^{L} \sum_{j=1}^{n} \sum_{i=1}^{m} W_{l j} u_{l j i}^{6} \\
& \sum_{l=1}^{L} X_{l i j} \leq d_{i j}, \forall i, j \\
& \sum_{j=1}^{n} x_{1 i j} \leq c a_{1 i}, \forall i, 1 \\
& \sum_{j=1}^{n} \sum_{i=1}^{m} x_{1 i j} \leq \alpha y_{1}, \forall I \\
& \sum_{l=1}^{L} W_{1 j}=1, \forall, j
\end{aligned}
$$

Constraint (13) define unit demand for products $i$ for customers $j$, (14) describe the capacity constraint for products $i$ for locations $l$. Constraint (15) premise that a location is indicate when and only if there is a demand for any product. Constraint (16) denoteseach customer assigned to exactly one distribution center.

\subsection{Producer-DistributorCoordinated Model}

We study the earlier non-coordinated model in a supply chain coordination point of view where we assume that among the distributor, the retailer and the farmers take decisions jointly and the farmers and retailers decides to go for outsourcing to recover lost sales partially/completely, if possible. Any shortage leading to a lost sale is always detrimental even for the coordinated system as a whole and thus a cost (penalty) is always associated with it. Though, it is a channel penalty cost, here it is assigned to the farmer and retailer for its linear additive property. If $k 1(0<=k 1<=1)$ is the fraction of the demand shortfall that may be recovered by outsourcing or external procurement, the modified profit equations of the farmer, retailer and the distributor are respectively as follows:

$$
\begin{gathered}
Z_{1}=\sum_{l=1}^{L} \sum_{i=1}^{m} \sum_{j=1}^{n}\left[x_{l i j}+k_{1}\left(d_{i j}-x_{l i j}\right)\right]_{\mathcal{C}_{i j}} \\
Z_{3}=\sum_{l=1}^{L} \sum_{i=1}^{m} \sum_{j=1}^{n}\left[x_{l i j}+k_{1}\left(d_{i j}-x_{l i j}\right)\right]\left(S_{i j}-c_{i j}\right)
\end{gathered}
$$

Hence the coordination return is given by,

$Z=\sum_{l=1}^{L} \sum_{i=1}^{m} \sum_{j=1}^{n}\left[\left\{x_{l i j}+k_{1}\left(d_{i j}-x_{l i j}\right)\right\} \mathcal{C}_{i j}+\left\{x_{l i j}+k_{1}\left(d_{i j}-x_{l i j}\right)\right\}\left(S_{i j}-c_{i j}\right)\right.$

Which simplified, we have

$$
Z=\sum_{l=1}^{L} \sum_{i=1}^{m} \sum_{j=1}^{n}\left[(1-k 1) x_{l i j}+k_{1} d_{i j}\right] S_{l i}
$$

Therefore the coordination profit is given by:

$$
\begin{aligned}
& \text { Maximize, } Z=\sum_{l=1}^{L} \sum_{i=1}^{m} \sum_{j=1}^{n}\left[(1-k 1) x_{l i j}+k_{1} d_{i j}\right] S_{l i}-\left[\sum_{l=1}^{L} \sum_{j=1}^{n}\left\{\alpha_{l} w_{l j}+\left(c_{l i}+t_{l i}\right) r_{l i}\right\}+\sum_{l=1}^{L} \sum_{i=1}^{m} \sum_{j=1}^{n}\left(p_{l i j}+h_{l i j}+m c_{l}\right) x_{l i j}+\sum_{l=1}^{L} \sum_{i=1}^{m} l_{l i} \boldsymbol{v}_{l i}\right. \\
& +f_{l i} \boldsymbol{g}_{l i}^{*}+\boldsymbol{w}_{l i}^{*} \boldsymbol{g}_{l i}+\sum_{l=1}^{L} \sum_{i=1}^{m} y_{l} \boldsymbol{u}_{l i}^{1}+\sum_{l=1}^{L} \sum_{j=1}^{n} \sum_{i=1}^{m} x_{l i j}\left(\boldsymbol{u}_{l i j}^{2}+\boldsymbol{u}_{l i j}^{3}\right) \boldsymbol{x}_{l i j}+\sum_{l=1}^{L} x_{l} u_{l}^{4}+\sum_{l=1}^{L} \sum_{j=1}^{n} \sum_{i=1}^{m} x_{l i j} \frac{u_{l i j}^{5}}{2}+\sum_{l=1}^{L} \sum_{j=1}^{n} \sum_{i=1}^{m} \boldsymbol{w}_{l j} \boldsymbol{u}_{l i j}^{6} \\
& \text { Maximize, } Z=\sum_{l=1}^{L} \sum_{i=1}^{m} \sum_{j=1}^{n}\left[1-c_{i j}+\left(1-k_{1}\right)_{S_{i j}}^{*}\right] X_{l i j}+\sum_{i=1}^{m} \sum_{j=1}^{n} k_{1} S_{i j}^{*} d_{i j}-\left[\sum_{l=1}^{L} \sum_{i=1}^{m}\left\{X_{l} y_{l i}+\left(c_{l i}+t_{l i}\right) r_{l i}\right\}\right. \\
& +\sum_{l=1}^{L} \sum_{i=1}^{m} \sum_{j=1}^{n}\left(p_{l i j}+h_{l i j}+m c_{l}\right)_{X_{l i j}}+\sum_{l=1}^{L} \sum_{i=1}^{m}\left(1_{l i} V_{l i}+f_{l i} g_{l i}^{*}+W_{l i} g_{l i}\right) \\
& \left.+\sum_{l=1}^{L} \sum_{i=1}^{m}\left(r t_{l i}-r t_{l i}^{*}\right) d_{i j} p_{i j}+\sum_{l=1}^{L} \sum_{i=1}^{m} \sum_{j=1}^{n} X_{l i j} u_{l i j}^{2}\right]
\end{aligned}
$$


Remaining set of constraints are described in the above two non-coordinated models.

\section{Solution Approach and Numerical Example}

To find the solution of the formulated MILP model, we have solved the required model by using AMPL (AMPL Student Version 20121021) with appropriate solver MINOS. We have developed an AMPL code, which consists of an (a) AMPL model file, containing the actual program, (b) AMPL data file, containing data for the various parameters and (c) AMPL run file. This program has accomplished on a Core-I3 machine with a $3.60 \mathrm{GHz}$ processor and 4.0 GB RAM.

To analyze the effectiveness of the proposed models, we consider a numerical example, which consisting 5 production locations, 5 products and 2 customers (5L-5P-2C). The deterministic demand of unit products of customers are (4600, $3150,2550,2870,3500)$ and $(5600,2000,2200,4650,2700)$, producer fixed costs of per unit products (in BDT) for each locationsare $(14400,15400,15300,14500,15000),(13600$, $14600,14600,14500,15400),(13700,15800,14800,14700$, $14600),(13800,15700,15500,14600,14700)$, and $(14500$, $14600,14600,15500,15400)$, also wholesaler fixed costs of per unit products (in BDT) for each locationsare (14000, $15000,14000,13000,15000),(16000,16000,16000,15000$, $14000),(17000,18000,18000,17000,16000),(18000$, $17000,15000,16000,17000)$, and $(15000,16000,16000$, $15000,14000)$ respectively. All types of information don't existent here because of its large volume. The purpose of this example is to provide a consistent logistics support to the wholesaler as well as to find the suitable feasible location for the warehouse among the given set of locations, which optimize the supply chain.

\section{Result Analysis and Discussion}

In this section, fundamental findings regarding the numerical example of the proposed models as described in Table 1. Which provide the comparative analysis of the decision variables before and after coordination for complete or partially outsourcing. The percentage of the change of profit for various cases is obtained by the following formula:

$$
P I(\%)=\frac{(\text { Totalreturn-Totalinvestment })}{\text { Totalinvestment }} \times 100
$$

The individual profit of producer and distributor is calculated using the formula of described by Sajadieh and Jokag [19] and Goyal [20].

\subsection{When the Producer and Distributor take Decision in Individually (Without Coordination)}

The individual profit (percentage on investment) of the producer and distributor are given as,

Producer profit $=23.71 \%$, distributor profit $=30.54 \%$ and net profit $=54.25 \%$.

\subsection{When the Producer and Distributor Take Decision Jointly (with Coordination)}

When the value of $\mathrm{k} 1$ is assumed and the problem is solved using the solution procedure, whose results are tabulated in Table 1.

Table 1. Coordinated policy with various outsourcing.

\begin{tabular}{lllll}
\hline No. & K1 & $\begin{array}{l}\text { Producer } \\
\text { profit\% }\end{array}$ & $\begin{array}{l}\text { Distributor } \\
\text { profit\% }\end{array}$ & $\begin{array}{l}\text { Net } \\
\text { profit\% }\end{array}$ \\
\hline 1 & 0.1 & 23.42 & 33.86 & 57.28 \\
2 & 0.2 & 26.22 & 34.09 & 60.31 \\
3 & 0.3 & 27.38 & 34.18 & 61.56 \\
4 & 0.4 & 28.02 & 34.23 & 62.25 \\
5 & 0.5 & 28.42 & 34.26 & 62.68 \\
6 & 0.6 & 28.69 & 34.28 & 62.97 \\
7 & 0.7 & 28.89 & 34.30 & 63.19 \\
8 & 0.8 & 29.05 & 34.31 & 63.36 \\
9 & 0.9 & 29.17 & 34.32 & 63.49 \\
10 & 1.0 & 29.26 & 35.03 & 64.29 \\
\hline
\end{tabular}

The result shows that maximum profit is obtained for the coordinate policy when $\mathrm{k} 1=1$ that is for complete outsourcing. Therefore it has become possible to outsource the entire shortage beneficially. It is also observed that as the value of $\mathrm{k} 1$ is increased the coordinated benefit is also increased.

The profit components of the different market players of the supply chain network are shown in Table 2.

Table 2. Net profit components of the different market players.

\begin{tabular}{lll}
\hline Market players & Net profit\% & Improvement with respect tonon-coordinate policy (percentage) \\
\hline Distributor & 35.03 & 4.49 \\
Producer & 29.26 & 5.55 \\
Coordinated benefit & 64.29 & 10.04 \\
\hline
\end{tabular}

Therefore, after coordination for complete outsourcing, the coordinated benefit is increased by $10.04 \%$. Also the producer benefit $(5.55 \%)$ is increased more than the distributor benefit (4.49\%).

Figures 1 and 2 describe the average demand of different products achieved by MILP model for customer-1 and customer-2. The highest demand of the product for customer-1 is product 3 which is followed by product 5 . The highest demand of the product for customer- 2 is product 4 which is followed by products $1,5,3$. Further,figure 1 satisfies the optimal demand of customer-1 by the manufactures located at the location points 1, 2, 4 and 5. Also, figure 2 satisfies the optimal demand of customer-2 by the manufactures located at the location points 1, 2, 3, 4 and 5. Proposed model illustrates that customer-2 located at locations 3 and 5 is profitable for four products, which is followed by locations 1,4 and 2 . 


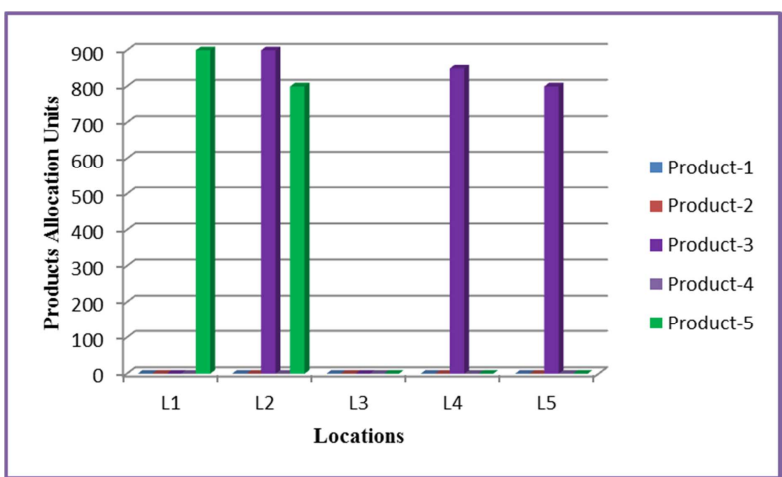

Figure 1. The demand of different products at different locations for customer-1.

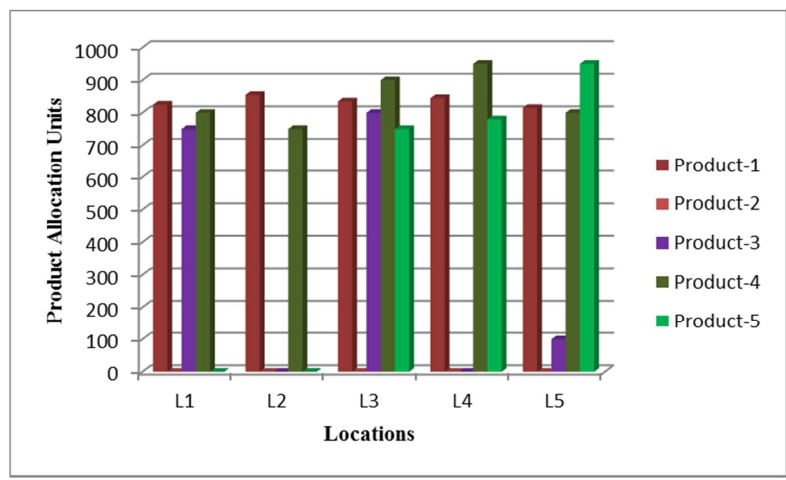

Figure 2. The demand of different products at different locations for customer-2.

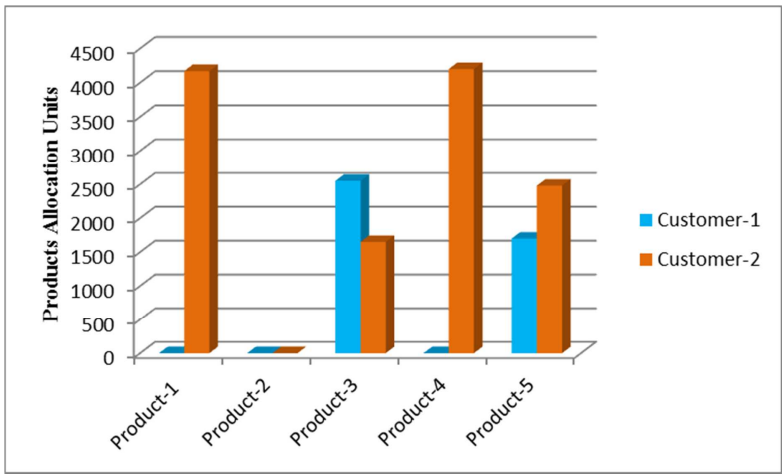

Figure 3. The demand of different products at different locations for customer 1 and 2 .

Figure 3 shows that product 1, 3, 4 and 5 are optimal for customer 2. Also product 3 and 4 are optimal for customer 1. Products 3 and 5 are optimal for both customers. Further, product 2 is not anyhow optimum for both customers.

\section{Conclusion}

In this research, three MILP based models are developed for the coordinated supply chain network and solved these models by using AMPL with appropriate solver MINOS. In this paper, we assumed the insufficient production capacity of the producer as the reason for shortages; it has been shown that total coordinated profit may be improved by outsourcing. The formulated models simultaneously maximize the profit.
Some of the significance findings can be summarized as follows:

The illustrated numerical example shows that maximum profit is obtained for the coordinate policy when $\mathrm{k} 1=1$ that is for complete outsourcing. It is also observed that as the value of k1 is increased the coordinated benefit is also increased. Therefore, after coordination for complete outsourcing, the coordinated benefit is increased by $10.04 \%$. Also the producer benefit $(5.55 \%)$ is increased more than the wholesaler benefit (4.49\%).

The work may also be expanded along a more progressive environment considering production and demand uncertainty.

\section{Acknowledgements}

I am highly thankful to the University Grants Commission of Bangladesh, for the provided financial support during my research work.

\section{References}

[1] Brandenburg, M. et al., Quantitative models for sustainable supply chain management: Developments and directions. European Journal of Operational Research, 233, (2014) 299312 .

[2] Wang, G., Huang, S. H. \&Dismukes, J. P., Product-driven supply chain selection usingintegrated multi-criteria decisionmaking methodology. International Journal ofProduction Economics, 91, (2004) 1-15.

[3] Nickel, S., Saldanha-da-Gama, F. \& Ziegler, H. P., A multistage stochastic supplynetwork design problem with financial decisions and risk management. Omega, 40, (2012) 511-524.

[4] Papageorgiou, L. G., Supply chain optimisation for the process industries: Advancesand opportunities. Computers and Chemical Engineering, 33, (2009) 1931-1938.

[5] Gupta, A. \&Maranas, C. D., Managing demand uncertainty in supply chain planning. Computers \& Chemical Engineering, 27, (2003) 1219-1227.

[6] Klibi, W., Martel, a \& Guitouni, a. The design of robust valuecreating supply chainnetworks: A critical review. European Journal of Operational Research, 203, (2010) 283-293.

[7] Guillén-Gosalbez, G. \& Grossmann, I. E., Optimal design and planning of sustainablechemical supply chains under uncertainty. AIChE Journal, 55, (2009) 99-121.

[8] Sundarakani, B. et al., Modeling carbon footprints across the supply chain. InInternational Journal of Production Economics, 128, (2010) 43-50.

[9] Ramudhin, A. et al., Carbon Market Sensitive Green Supply Chain Network Design. 2008 IEEE International Conference on Industrial Engineering and EngineeringManagement, (2008) pp. 1093-1097.

[10] Hassini, E., Surti, C. \& Searcy, C., A literature review and a case study of sustainablesupply chains with a focus on metrics. International Journal of Production Economics, 140, (2012) 69-82. 
[11] Bojarski, A. D. et al., Incorporating environmental impacts and regulations in a holisticsupply chains modeling: An LCA approach. Computers and Chemical Engineering, 33,(2009) $1747-1759$.

[12] Wang, F., Lai, X. \& Shi, N., A multi-objective optimization for green supply chainnetwork design. Decision Support Systems, $51,(2011) 262-269$.

[13] Akkerman, R., Farahani, P. \&Grunow, M., Quality, safety and sustainability in fooddistribution: a review of quantitative operations management approaches andchallenges. $O R$ Spectrum, 32, 863-904.

[14] Ahumada, O. \& Villalobos, J. R., 2011. A tactical model for planning the productionand distribution of fresh produce. Annals of Operations Research, 190, (2011) 339-358.

[15] Rong, A., Akkerman, R. \&Grunow, M., An optimization approaches for managing freshfood quality throughout the supply chain. International Journal of Production Economics, 131, (2011) pp. 421-429.

[16] Aung, M. M. \& Chang, Y. S., Traceability in a food supply chain: Safety and qualityperspectives. Food Control, 39, (2014) 172-184.

[17] Van der Vorst, J., Tromp, S. O. \& Zee, D.-J. Van der, Simulation modeling for foodsupply chain redesign; integrated decision making on product quality, sustainability andlogistics. International Journal of Production Research, 47, (2009) 6611-6631.

[18] Shukla, M. \&Jharkharia, S., Agri-fresh produce supply chain management: a state-ofthe-art literature review. International Journal of Operations \& Production Management, 33, (2013) 114-158.

[19] Goyal, S. K., An integrated inventory model for a Single supplier-single customer problem, International Journal of Production Research, 151 (1976) 107-111.

[20] Sajadieh, M. S. and Jokar, M. R. A., Optimizing shipment, ordering and pricing policies in a two stage supply chain with price sensitive demand, Transportation Research Part E, Vol. 45, (2009) 564-571.

[21] Drezner, Z., and Hamacher, H. (eds.), Facility Location: Applications and Theory, Springer Verlag, Berlin, 2002.

[22] Hung, B., and Liu, N., "Bilevel programming approach to optimizing a logistic distribution network with balancing requirements", Transportation Research Record: Journal of the Transportation Research Board, 1894 (2004) 188-197.

[23] Jose, C. S., Haider, A. B., Rui, B., and Alexandre, S., "A multi objective approach to solve capacitated vechile routing problems with time windows using mixd integer linear programming", International Journal of Advanced Science and Technology, 28 (2011) 1-8. 